\title{
A tradução como procedimento poético de repetição
}

\author{
Maria Sílvia Cintra Martins* \\ "A linguagem fala da linguagem" \\ "A escritura é sempre crítica, por necessidade vital, para descobrir sua \\ própria historicidade" \\ (Henri Meschonnic, 1989)
}

RESUMO: Apresento resultados de pesquisa que se deteve, em princípio, em torno da obra de Henri Meschonnic $(1989 ; 2010)$ e de Raduan Nassar $(1975 ; 2016)$. A pesquisa teve como objetivo inicial a comparação da obra Lavoura Arcaica com sua tradução para a língua inglesa. Os resultados apontam, por um lado, para o apagamento da relação da obra original com obras com que dialoga; por outro, para a necessidade de se pressupor o eixo de tradução poética, no que implica procedimentos de repetição.

Palavras-chave: tradução; poética; repetição.

ABSTRACT: I bring results of research on the works of Henri Meschonnic (1982; 2010) and Raduan Nassar $(1975 ;$ 2016). The initial research objective was the comparison of the book Lavoura Arcaica with its translation into English. Results point, on one hand, to the erasement of the relation existing between the original book and the texts with which it dialogues; on the other hand, to the necessity of pressupposing the axe of poetic translation which implies repetition procedures.

Keywords: translation; Poetics; repetition.

\section{Introdução}

Neste trabalho, de teor relativamente ensaístico, pretendo me debruçar sobre a forma de tradução que faz parte do próprio quefazer do literato. Sendo assim, partirei, em princípio, da diferenciação de Jakobson (1959), entre as três vertentes de tradução, apenas para mostrar que não é delas que se trata. Peço licença ao leitor, e aos avaliadores de trabalhos científicos em geral, pois este trabalho necessita comportar o teor razoavelmente ensaístico que comportará, para poder, de fato, dizer aquilo a que se pretende. $\mathrm{O}$ excesso de definições e de interrupções tornaria a caminhada fragmentada; é, no entanto, de preferência o descrédito na tematização, tal qual sinaliza Levinas (2017 [1963]), que me guia. Também a crença em que a gestualidade da linguagem significa, de preferência a cada palavra isoladamente (MESCHONNIC, 2010).

\section{As três formas de tradução}

Em capítulo continuamente citado nos Estudos de Tradução, Jakobson (1959) explicita três vertentes de tradução, em diferenciação hoje corriqueira, mas que, à época,

\footnotetext{
* Professora associada do Departamento de Letras da Universidade Federal de São Carlos.
} 
comportava novidade. A tradução interlinguística seria aquela que, até então, guardava para si a denominação de tradução, como se fosse a tradução propriamente dita. Traduzir seria verter termos, períodos, textos de um para outro idioma, de uma para outra língua, algo que podemos evidenciar, por exemplo, entre antropólogos que, ao iniciar contato com alguma comunidade até então desconhecida, teriam que aprender a nova língua, buscando para ela equivalentes na sua língua materna. Ou entre arqueólogos, que, descobrindo textos antigos em língua desconhecida até então, tratariam de desvendar seus significados através de uma série de comparações com termos de línguas que lhes fossem contemporâneas. Ou, ainda, entre turistas, simplesmente, que se veriam na necessidade de compreender e de se fazer compreender em outros países, no contato com outros povos, outras línguas e culturas.

Jakobson trazia, no entanto, a novidade de se começar a falar em tradução também no âmbito de uma mesma língua, ali onde costumamos nos referir às paráfrases e retextualizações. Como dizer - por assim dizer - as mesmas coisas em outras palavras. Por assim dizer, pois a cada nova materialização estamos sempre dizendo outras coisas, algo inerente, afinal, a toda a tradução, daí sua tendência constante à infidelidade, já que as palavras e suas ordenações são sempre únicas e, mesmo no âmbito de uma mesma língua, se dizemos certas coisas com outras palavras, já não são as mesmas coisas que dizemos. Este tra- da tra-dução está sempre nos conduzindo, nos transportando para um outro lugar, mesmo que apenas ligeiramente diferente. Autores como o linguista da enunciação francês Antoine Culioli, ou como o nosso eminente linguista Carlos Franchi falaram da tradução nesse sentido, no sentido do trabalho que se faz com a linguagem na medida em que a manipulamos epilinguisticamente.

Outra dimensão, ainda, seria aquela da tradução intersemiótica, algo que Jakobson derivava da intuição saussureana, de que há um campo mais amplo, que é o da semiose e das linguagens em geral, no qual se insere o trabalho linguístico propriamente dito. Sendo assim, a tradução intersemiótica nos conduziria de uma para outra dessas várias linguagens, como no caso, por exemplo, da passagem da linguagem verbal para a não-verbal, ou vice-versa. Traduzir, nesse sentido, passa a ser algo que transcende as palavras.

Antes de tocar na outra tradução na qual pretendo me ater, aproveito o momento da ampliação do escopo do que possa ser tradução - primeiro entre línguas, depois nos interstícios de uma mesma língua, e depois entre diferentes sistemas semióticos - para lembrar que, na linha do pensamento de Lotman (2005), podemos, ainda, falar da tradução como de algo que se dá, não só na semiosfera, ou seja, no âmbito das linguagens humanas, da semiose em geral, mas, também, na bioesfera e na noosfera, conforme contempladas na obra do filósofo, biólogo e geólogo russo Vladímir Vernádski (1863-1945) de cuja teorização Lotman teria partido para definir a semiosfera. Se assim for, a tradução diz respeito à vida em geral e às transformações e impregnações contínuas entre seres vivos. De alguma forma, é essa mesma ampliação que pode nos conduzir de volta à linguagem e à tradução que nos interessará em particular, e da qual me aproximarei mais adiante por meio do conceito oswaldiano de antropofagia.

\section{A tradução como procedimento poético de repetição}

Para falar dessa outra forma de tradução à qual pretendo me referir aqui - algo que derivo do pensamento de alguns autores que aqui menciono, sem que eles próprios a tenham tematizado - creio ser importante, em princípio, pensarmos na literatura como pertencente ao âmbito da repetição; nessa medida, se é fato, como nos alerta o linguista francês Henri Meschonnic (1989), que a linguagem poética dialoga em fluxo contínuo - 
contínuo porque permanente e também porque desprovido de compartimentações - com a linguagem do cotidiano e, até mais do que isso, que é a linguagem poética que vai nos pôr em questão a denominação que atribuímos a certa forma de linguagem como linguagem do cotidiano - se isso é fato, isso se dá porque o âmbito do poético é o âmbito privilegiado da repetição. Lembro, com Deleuze (1988, p. 460), e pensando na literatura enquanto arte: "A arte não imita, mas isso acontece, primeiramente, porque ela repete, e repete todas as repetições, conforme uma potência interior (a imitação é uma cópia, mas a arte é simulacro, ela reveste as cópias em simulacros)".

É fato que Henri Meschonnic não chega a desenvolver esta vertente de forma explícita; porém, é trazendo-se à tona toda essa complexidade inerente à poética, que alertamos para o fato do quanto as tão mencionadas categorias da intertextualidade, do dialogismo e da polifonia - para mencionar algumas questões teóricas mais corriqueiras - mostram-se insuficientes para que nos demos conta do que está em jogo no jogo da linguagem que o poético comporta. Também para isso, seria necessário, de fato, alertarmos para a centralidade do signo poético na compreensão do funcionamento da linguagem, contrariamente ao que temos feito de forma mais constante, ou seja, quando consideramos a linguagem naquele funcionamento dito convencional - porque não literário - para, a partir dele, pensarmos nos desvios ou na carnavalização que o trabalho poético comportaria.

Julia Kristeva vem sendo criticada ou até condenada por sua forma de tradução, na França, da obra de Mikhail Bakhtin, que jamais teria falado em intertextualidade, termo que Kristeva trouxe como tradução para o dialogismo ou a polifonia bakhtiniana, na medida em que inseriu em sua tradução a sua própria interpretação a respeito do que o filósofo russo estaria querendo dizer. Questões, de resto, interessantes, mesmo que não tanjam o âmbito do poético, mas pelo que comportam da dificuldade - e às vezes impossibilidade -, dos meandros, enfim, de toda tradução, que traria sempre e inevitavelmente a marca do olhar interpretativo do tradutor, já que, afinal, as palavras, por si mesmas, não significam, como cada vez mais aprendemos por meio da tradução e da crítica que lhe é própria.

Se há, de toda forma, algo que podemos denominar polifonia, dialogismo ou mesmo intertextualidade nos textos poéticos, são aspectos que se detectam na sua superfície como indícios de procedimentos mais profundos, procedimentos de tradução. A postulação da tradução como crítica, assim como aquela da crítica do e pelo ritmo (MESCHONNIC, 1982), abrem-nos a possibilidade de visualizarmos a dimensão da repetição, ali onde não se trata apenas de dialogar com o outro (muito embora este fenômeno esteja sobremaneira presente), nem se trata apenas de nos darmos conta da presença de múltiplas vozes (sempre presentes), nem de dizer, por exemplo, que o texto seria como que uma colcha de retalhos, em que se juntam diferentes palavras provindas de outros textos. Tudo isto está presente; porém o fenômeno da escritura transcende estes aspectos, transborda-os, e é para este fato que pretendo alertar aqui.

Talvez porque seja necessário falar do corpo e da História como de questões que fazem parte, de forma imbricada (e não externa), de todo esse processo. Aproximamonos, de resto, daquilo a que Carlos Franchi (1992), em seu texto clássico sobre a linguagem como atividade constitutiva, nos apontava como dimensão de pesquisa ainda não resolvida, algo que diria respeito ao aspecto heurístico e criativo presente na linguagem, e para cuja compreensão, de forma precisa e simultaneamente respeitosa, nosso linguista vai descartando diversos enfoques teóricos, sejam o gerativista transformacional chomskiano, seja o funcionalista, como insuficientes para dar conta do que estaria em nosso horizonte. Franchi de forma mais cautelosa, Meschonnic em sua linguagem transbordante e serial killer (DEGUY, 2001), ambos apontam para a 
dimensão criativa inerente à linguagem, mas, talvez por ser também poeta, o linguista francês vai além, na defesa de que é no signo poético que necessitamos vislumbrar o funcionamento dessa dimensão.

A linguagem poética como a linguagem que é própria do ser humano, mesmo porque é nela e através dela que se constrói e se inventa, continuamente, o pensamento (MESCHONNIC, 2010); como aquela que põe em questão a existência de algo que se chamaria "linguagem do cotidiano", ou a própria validade de sua definição (MESCHONNIC, 1989).

Se os textos são polifônicos ou dialógicos, isso não acontece, consequentemente, pelo fato de que estaríamos continuamente retomando as palavras alheias, mas porque estamos continuamente retrabalhando, criticando - naquele sentido de destruição e de construção simultâneas que toda crítica genuína comporta. Por isso mesmo, temos a tradução como crítica, e o ritmo como crítica do ritmo, mesmo porque, a cada instante, cada um de nós subjetiva a linguagem, critica-a e a retoma, dentro do ritmo que nos é pessoal. Notemos, mais uma vez, o quanto falar dos processos rítmicos e tradutórios inerentes à linguagem provoca um distanciamento e um aprofundamento das definições mais corriqueiras a respeito da linguagem, que, de forma às vezes mais, às vezes menos inadvertida, acabam, ainda, falando dela como de uma mosaico em que se juntam partes, como se tivéssemos em mãos apenas um caleidoscópio que nos caberia girar e girar, conseguindo diferentes composições, porém todas limitadas e previsíveis, mesmo porque as formas de encaixe já estariam dadas de antemão.

Para finalizar este item, antes de propor alguns exemplos, cabe lembrar em que medida a categoria da antropofagia pode nos interessar, e nos interessa. Diria, assim, que estamos sempre, no que concerne ao texto poético, diante de procedimentos canibalísticos e antropofágicos, desde que os entendamos como procedimentos antropológicos em que a vida e o corpo estão sempre presentes, ou seja, as palavras passam por meu corpo, eu as integro, rumino-as, mastigo-as e as devolvo, retrabalhadas. Esse processo pode envolver a paródia, mas não necessariamente, já que a paródia é apenas um caso possível dessa devoração contínua, que não tem começo nem fim: estará sempre presente, onde nós, seres humanos, estamos, em constante simbiose entre o que chamamos de espiritualidade, corporalidade, intelecto e emoções.

É nesse sentido, aliás, que o texto poético adquire centralidade nos estudos da linguagem, pois se tudo na linguagem é devoração, trabalho e reinvenção contínua, tudo tende ao poético; quando isso não acontece, então é porque, em tais casos - neles, sim reside a exceção, ou o desvio, e não o contrário.

Por isso tudo, trarei adiante exemplos extraídos do cotejo da obra de Raduan Nassar com outras obras, chamando a atenção para processos de devoração e de tradução que não se centram, nesses casos, na ironia, nem na paródia, de modo a mostrar, entre outros aspectos, que a antropofagia as transcende, se nos interessar, de toda forma, lidar com esse conceito quando queremos aludir ao trabalho criativo com a linguagem, que é o trabalho contínuo da diferença (como "différence" e "différance") e da repetição.

\section{De como a Lavoura Arcaica repete Totalidade e Infinito e Antígona}

Pegarei, para exemplificar os processos de tradução poética, esta obra monumental, Lavoura Arcaica, do escritor brasileiro ainda não conhecido e homenageado da forma que lhe será necessária, Raduan Nassar.

Minha primeira leitura da Lavoura se fez daquela forma inebriante, em que vamos mergulhando nas palavras ou sendo levados pelo empuxe em que nos carregam. Veio depois o filme de Luís Fernando de Carvalho, que, em parte, elucidou algumas 
questões, particularmente nas cenas iniciais; em parte, pelo poder de captação das imagens, passou a se impor como leitura e tradução da obra original. Anos se passaram, com o livro fechado, até que a tradução para o inglês, no ano de 2016, como Ancient Tillage, chamou minha atenção, já a partir do título, pois a palavra "arcaica", tão chamativa, havia desaparecido. Efetuei, a partir disso, um cotejo minucioso entre a obra original e a tradução de Karen Sotelino, para concluir pelo apagamento, na versão em língua inglesa, de certa repetição que a obra de Nassar comporta, aquela repetição para a qual chamo a atenção neste trabalho, denominando-a, também, de tradução. Ou seja: Lavoura Arcaica comporta, em suas linhas, a tradução poética de outras obras; no entanto, a tradução literária que dela se fez em língua inglesa tende para o apagamento dessa tradução primeira, implícita na obra de Nassar.

Foi, de toda forma, no procedimento comparativo entre a obra original e sua tradução recente para a língua inglesa, que - exatamente pelo componente crítico da inserção no texto, que os processos tradutório e comparativo comportam - pude desvendar certos procedimentos de tradução na obra de Nassar, nesse exato sentido para o qual quero chamar a atenção aqui. Percebi, à medida que comecei um levantamento vocabular nas linhas da Lavoura, primeiro com os termos "lavoura" e "arcaica", depois como vários outros, como "traço", "partir", "rosto" - na medida em que um achado ia me conduzindo no rastreio de outros - primeiro a comunicação implícita da Lavoura com a tragédia clássica sofocleana Antígona; depois, seu diálogo com a filosofia e a metafísica de Emmanuel Levinas, particularmente com Totalité et Infini.

É, no entanto, nesse ponto, que os termos "comunicação" ou "diálogo" se mostram insuficientes para nos explicar os procedimentos de tradução e de repetição inerentes à escritura. Toda explicação que se dê de forma externa à obra se mostrará, de resto, insuficiente. Há algo nas entranhas da Lavoura que remete à Antígona e à Totalidade e Infinito, algo que enxergamos, como se estivéssemos, de preferência, diante das transparências de Monet, de seus nenúfares, e não diante de parimpsestos: já que não se trata de executar raspagens ou de levantar camadas para poder enxergar superposições. Tudo está lá, para ser visto, a olho nu.

Certamente não se trata de falar em influências de um autor sobre o outro; nem mesmo apenas de diálogos. São obras que se traduzem mutuamente, sem começo nem fim, sem antes nem depois, sem causa e efeito: dentro da falação inerente a toda linguagem, em que as palavras continuamente se retomam, se repetem e se transcendem. As palavras trabalham continuamente, umas sobre as outras, umas dentro das outras, em reflexos, espelhamentos e refrações constantes, mas de tal forma e de tal maneira, que uma passa a residir dentro da outra. O diálogo é interno, implícito: não ontológico, mas, de preferência, metadiscursivo. Não chegamos com ele a definições, mas a constatações de fenômenos, que, por serem constantes, não se deixam estabilizar.

Talvez, até mesmo nesse sentido, a literatura repita a vida, dirigindo-se a nossa forma distraída de viver, no trabalho constante voltado à distribuição de traços, como aqueles de que a Lavoura fala e com os quais se deixa construir. A repetição e a tradução dão-se, assim, em diversas direções: a obra traduz a vida e se traduz a si mesma, à medida que traduz, ainda, outras obras, das quais escolhi apenas duas para tratar aqui.

Por outro lado, se mencionamos a antropofagia, categoria, em princípio, própria à área de estudos da Antropologia, podemos pensar, ainda, nesse mesmo âmbito da repetição, na mitologia, na medida em que colocar a Lavoura Arcaica nesse labirinto tradutório pode significar colocá-la como mais um entre tantos mitos, dentro do processo transformacional inerente aos mitos, à mitologia em geral. Transformação como operação estética e dinâmica, e não lógica ou algébrica. Pois todo mito é uma 
versão de outro mito, todo outro mito abre para um terceiro e quarto mitos; mito como máquina de sentido: um instrumento para converter um código em outro, projetar um problema sobre um problema análogo, fazer circular a referência, contraefetuar anagramaticamente o sentido (VIVEIROS DE CASTRO, 2015, p. 243).

Um dos aspectos que me fez, de toda forma, aproximar a Lavoura da tragédia grega foi o embate, presente em ambas as obras, entre selvageria e civilização (entre a hybris e a lei, o caos e a pólis), de que Rosenfield (2016) trata de forma muito acurada no seu elogio da tradução de Hölderlin para a Antígona sofocleana. Metonimicamente, Nassar faz referência a esse embate em trechos do capítulo 7 em que, primeiro, remete à ordem dos lençóis no roupeiro (que, segundo André, estariam morbidamente impregnados das palavras do pai, as quais, conforme sabemos, remetem, com seu teor teológico-político, à ordem típica do que se espera de um mundo dito civilizado); depois, ao uso ambivalente das mesmas roupas reencontradas no cesto do banheiro.

No diálogo arquitetural da Lavoura com a Antígona, podemos falar de Ana como de uma Antígona neófila, “(...) dominando a todos com seu violento ímpeto de vida" e, nessa medida, contradizendo e desobedecendo publicamente (mas não como mártir, ou seja, tal qual a Antígona de Sófocles reconstruída por Hölderlin) o (s) decreto (s)/édito (s) de Iohana/Creonte. Muito interessante, de resto, notar a forma com que ambas as protagonistas, Antígona e Ana, se contrastam (e se comunicam), metonimicamente, ao final de cada uma das narrativas: a primeira, "suspensa pelo pescoço/ enforcada com um lenço de finíssimo linho" (na tradução de Donaldo Schüler; "pendente (...), estrangulada em laço improvisado com seu próprio véu de linho", na tradução de Gama Kury); enquanto a outra, com "a gargantilha de veludo roxo apertando-lhe o pescoço (...)" (NASSAR, 1989, p. 186), trecho traduzido na língua inglesa - e de forma apagante - como: "(...) a purple velvet choker around her neck" (NASSAR, 2016).

Ana ganha, assim, frente a Antígona, e em espelho, camadas de profundidade, e podemos passar a vê-la, em função da exploração desses indícios, como a heroína que, tal qual Antígona - mas de forma sui generis - desafia a morte com ousadia. São dignos, de nota, ainda, em Antígona, no momento em que Hêmon está para morrer, o excerto "Ainda/ na posse de si, estende os braços lânguidos à noiva, estreita-a/ e numa golfada lança-lhe uma impetuosa corrente/ de rubro líquido no lívido rosto", que podemos contrastar com o momento em que Ana, dançando no centro de todos, "sempre mais ousada, mais petulante, inventou um novo lance alongando o braço, e, com graça calculada (que demônio mais versátil!), roubou de um circundante a sua taça, logo derramando sobre os ombros nus o vinho lento (...)".

O diálogo com Emmanuel Levinas, por sua vez, aprofunda nossa compreensão de tudo o que está, prismaticamente, em jogo, ou seja, não precisamos optar entre Sófocles ou Levinas para nossa conversa com Nassar; podemos trazê-los juntos para esta sinfonia/ polifonia com Nassar, algo que o sincretismo próprio à obra literária nos permite. Lembro, a propósito, que a reflexão levinasiana sobre o acolhimento, além do processo parafrástico e tradutório em que esse termo vai reverberando sobre outros termos - hospitalidade, atenção, recolhimento - espraia-se, ainda, sobre os eventos da carícia e da feminidade - "la Femme de la Maison" -, da "demeure", da habitação, muito embora "rosto" e "Eros" entrem em contraposição, conforme veremos mais adiante. A hospitalidade é passividade, já que a hospitalidade ou a recepção implicariam, no pensamento levinasiano, o receber para além da capacidade do Sujeito:

É, pois, receber do Outro para além da capacidade do Eu; o que significa exatamente: ter a ideia do Infinito. Mas isso significa também ser 
ensinado. A relação com o Outro ou o Discurso é uma relação nãoalérgica, uma relação ética; esse discurso acolhido é, porém, um ensinamento (LEVINAS, 2017, p. 43, itálico do autor).

Do lado da Lavoura Arcaica, vários receberes se entrecruzam, pois sabemos, entre outros aspectos, que Nassar nos contempla com uma escrita de nos tirar o fôlego, conforme já tem sido salientado - às vezes, até, negativamente, apontando-se que seria excessiva nossa imersão como leitores em um mundo de desrazão, de alucinação, que nos extrairia a capacidade de julgamento. O Capítulo 17 da Lavoura, que versa sobre o Tempo na perspectiva (óptica ou ética) de André, e que prenuncia o que acontecerá entre os irmãos no Capítulo 20, nos contempla com a presença da casa velha (a "habitação"), da porta, e também do rosto, além da referência às pombas que, conforme apontei alhures, podem fazer o papel da presa presente no discurso filosófico na alusão ao Tempo, aos traços e vestígios de algo que se quer compreender, captar, capturar (MARTINS, no prelo). Se a obra de Nassar só se dá e se entrega na certeza de nosso acolhimento e hospitalidade, muito embora nos contemple com algo que estaria além de nossa capacidade de recepção - ou seja, o próprio quefazer artístico se apresenta, nesse caso, como Metadiscurso, Discurso de seu próprio discurso e dos discursos de seus heróis -, há, ainda, outras receptividades, outra hospitalidade, que passa pela passividade de Ana, mas também pela abertura da porta por André - e seu posterior fechamento. Assim como Ana se abre, mas depois se fecha em copas, para além da porta da capela.

Portas e mais portas abrem-se e se fecham, de resto, e também podem permanecer apenas como portais, a sinalizar algo que não se pode transgredir ou ultrapassar. Logo no início do romance, temos "o ruído das batidas na porta", quando André encontra-se recolhido na pensão interiorana; há a porta do quarto de infância, que se abre para dar entrada a "um vulto maternal e quase aflito"; há a menção do pai, em seus sermões, à união da família, "não nos afastando da nossa porta"; há a intenção de André de mandar que o irmão fosse embora de sua pensão, "e fecharia a porta"; há o risco trazido pela sua eventual doença epilética, de as portas terem que ser vedadas: "você tem um irmão epilético, fique sabendo, volte agora pra casa e faça essa revelação, volte agora e você verá que as portas e janelas lá de casa hão de bater com essa ventania ao se fecharem"; há o que se esconde por detrás das portas - "escondendo o medo de meninos detrás das portas"; há o perigo de algo se insinuar, apesar das portas, por suas frestas: "insinuando-se sorrateiramente pelas frestas das nossas portas e janelas"; há a porta que André fecha, como que aprisionando Ana: "fechei a porta, tinha puxado a linha, sabendo que ela, em algum lugar da casa, imóvel, de asas arriadas, se encontraria esmagada sob o peso de um destino forte"; e há, ainda na primeira parte da obra, o momento da partida, de deixar para trás as terras da fazenda, "os muros e as portas da cidade", em que podemos sentir a alusão às portas de Tebas, e a Antígona.

$\mathrm{Na}$ perspectiva de Levinas, encontramos o rosto, o Infinito e o acolhimento, que remetem ao que existiu desde sempre, que sempre esteve e ao qual se tem acesso no imediato do presente:

A noção de rosto à qual recorreremos em toda esta obra abre outras perspectivas [em contraste com a ontologia subjetivista]: ela nos leva em direção a uma noção de sentido anterior à atribuição de significado/categorização ["Sinngebung"] (...). Ela permite, enfim, descrever a noção do imediato (LEVINAS, 2017, p. 44). 
O romance, por sua vez, prossegue:

(...) o tempo, o tempo, esse algoz às vezes suave, às vezes mais terrível (...) é ele ainda hoje e sempre quem decide e por isso a quem me curvo cheio de medo e erguido em suspense me perguntando qual o momento, o momento preciso da transposição? (...) que massa de vento, que fundo de espaço concorrem para levar ao limite? (...) ela estava agora diante de mim, de pé ali na entrada, branco branco o rosto branco (...) (NASSAR, 1989, pp. 97-98).

No instante do face-a-face, é a ciência de menino, no entanto, a astúcia destra de menino que se interpõe para resolver o impasse, que na linha de Levinas se resolveria pela testemunha justa e ética do terceiro: “(...) um nó cego nas nossas mentes, mas bastava que ela transpusesse a soleira, era uma ciência de menino, mas já era uma ciência feita de instantes (...)" (NASSAR, 1989, p. 98). A linguagem literária permite, entretanto, a dubiedade ou a plurivalência, de tal forma que podemos dizer que Nassar nos mostra, simultaneamente, a Justiça e sua contradição, já que temos em Ana, tanto a alusão à personagem da irmã de André e, nesse sentido, à perversão - na linha do pensamento de Levinas - como a alusão à "Femme de la Maison" e, nesse sentido, à busca e ao encontro do Infinito.

Se todas essas questões estão interligadas no discurso filosófico de Levinas recolhimento, acolhimento, hospitalidade, rosto -, exatamente como a forma escolhida pelo autor de evitar o recurso à tematização, vejamos, em mais detalhe, como "acolhimento" e "recolhimento" comparecem na obra de Nassar. A primeira página da Lavoura Arcaica traz o termo "acolhimento" em sequência de teor negativo, e esta é, de fato, sua única ocorrência: trata-se do "disperso e esparso torvelinho sem acolhimento", na referência ao estado do personagem André após o ato de masturbação, que dá início à narrativa e ganha mais visibilidade no filme de Carvalho. A sequência frástica em torno do verbo "colher", por sua vez, aludira ao fato acontecido logo antes das batidas na porta com a chegada do irmão Pedro: “(...) o quarto é individual, é um mundo, quarto catedral, onde, nos intervalos da angústia, se colhe, de um áspero caule, na palma da mão, a rosa branca do desespero" (NASSAR, 1989, p. 7).

Embora a forma de ocorrência de ambos os vocábulos - "acolhimento" e "colher" - pareça contradizer as ideias presentes em Levinas no que se refere ao acolhimento, ou estar em sua contramão, vale lembrar, de toda forma, as ponderações do filósofo em torno do mal e da angústia: "O excesso do mal, pelo qual ele excede ao mundo, é também nossa impossibilidade de aceitá-lo. A experiência do mal seria, portanto, também nossa espera do bem - o amor de Deus". Dentro desse aparente convívio entre o Bem e o Mal, que aqui se traduziria no convívio entre "acolhimento" e "não acolhimento", Levinas aponta para "A revelação. (...) Abertura do Bem que não é uma simples inversão do Mal, mas uma elevação" (LEVINAS, 2008, p. 179 e 182). Quem sabe, alegoricamente, é a isso que a transformação/revelação de Ana, ao final da narrativa de Nassar, busca aludir. Ana, alma gêmea de André. Talvez - além das questões implícitas ao discurso apologético e envolvente de André - esteja nessa Glória e Elevação, que se dão por meio de Ana, o motivo pelo qual tendemos a nos alinhar com André, a perdoá-lo, a reconhecê-lo em sua verdade.

Se "acolher" e seus derivados dão-se em única ocorrência (e de forma negativa), "colher" prolifera-se na narrativa, assim como "recolher" e "escolher". Seguem aqui algumas amostras de "colher", que se dividem entre seu sentido mais primordial, de retirar algo da natureza, e alguma utilização de sentido lúbrico: "meu sono, quando 
maduro, seria colhido com a volúpia religiosa com que se colhe um pomo"; "as uvas e as laranjas colhidas dos pomares"; "sua mão quente e aplicada colhendo antes o cisco e logo apanhando e alisando meus cabelos"; "bastava afundar as mãos para colher o sono amarrotado das camisolas e dos pijamas"; "Tens de provar também esses figos acabados de colher da árvore"; "colherei, uma a uma, as libélulas que desovam no Teu púbis"; "quando já tivermos, debaixo de um céu arcaico, tingido nossos dentes com o sangue das amoras colhidas no caminho". Talvez a ocorrência de "colher" que mais se assemelha com o sentido de "acolher o Outro" seja aquela em que, ao se aproximar de André, que se encontra recolhido junto a um tronco, assistindo de longe à festa da família, sua mãe (que nesse momento confundimos vagamente com a irmã, em função da organização da frase) achega-se dele, com "sua mão quente e aplicada colhendo antes o cisco e logo apanhando e alisando meus cabelos". Mesmo esse "acolhimento" da mãe, em função de outras referências a sua forma de tratar o filho, não deixa de ter certo quê lúbrico, no entanto.

O "recolher" e o "recolhimento" (que sucederiam ao "acolhimento", segundo a lógica do filósofo) proliferam-se na obra de Nassar, atravessando os mais diferentes capítulos, no contato com diversos personagens e situações: André recolhe-se junto à árvore em movimento que mimetiza o da toalha que se recolhe - "era então que se recolhia a toalha antes estendida por cima da relva calma, e eu podia acompanhar assim recolhido junto a um tronco mais distante os preparativos agitados para a dança", cena que se repete, quase idêntica, em um dos capítulos finais; o recolhimento comparece no sermão de Iohana, próximo, talvez, da ideia bíblica do acolhimento - "é através do recolhimento que escapamos ao perigo das paixões"; o André adolescente recolhe-se na casa velha - "me recolhi na casa velha da fazenda"; o pai e Pedro se recolhem, à sua maneira, frente ao impacto da atitude agressiva de André; a noite recolhe-se logo após o relacionamento entre os irmãos, quando André já não encontra Ana - "gelando minha medula o recolhimento dessa noite escura"; os irmãos, André e Pedro, recolhem-se no retorno ao lar - "foi um longo percurso marcado por um duro recolhimento, os dois permanecemos trancados durante toda a viagem que realizamos juntos"; o recolhimento lança-se indireta e metonimicamente sobre Ana - "foi só você partir e ela se fechou em preces na capela, quando não anda perdida num canto mais recolhido do bosque"; também o Tempo recolhe: "ele próprio conhecendo seus caminhos, recolhendo e filtrando de vária direção o caldo turvo dos afluentes e o sangue ruivo de outros canais para com eles construir a razão mística da história".

A ocorrência de "escolha", por sua vez, fornece-nos a pista da óptica do literato, e seu questionamento ético, na boca do (anti) herói André: “(...) por que então esses caprichos, tantas cenas, empanturrar-nos de expectativas, se já estava decidida a minha sina?" (NASSAR, 1989, p. 117). Assim, se, em Levinas, "acolhimento", "recolhimento" e "rosto" completam-se e se traduzem, quando vamos no recolho da palavra "escolha" em Nassar, nos deparamos com duas ocorrências na contiguidade com "máscara", ou seja, na falta de escolha e diante do apelo irresistível de Eros, restaria ao sujeito abrir mão do rosto, e servir-se de máscaras: “(...) insisto em que não temos outra escolha, se quisermos escapar ao fogo deste conflito: forjarmos tranquilamente nossas máscaras, desenhando uma ponta de escárnio na borra rubra que faz a boca (...) (NASSAR, 1989, p. 133).

Para Levinas, é no acolhimento do Outro - e na sujeição ao Outro - que o ente encontra sua liberdade genuína, por paradoxal que pareça o fato de uma aparente falta de escolha poder tornar o homem livre; em Nassar, o herói trágico reconhece, em parte agoniado, mas em parte de forma cínica, sua falta de escolha e, simultaneamente, sua escolha pela concupiscência e pelo uso de máscaras - provavelmente, de forma a 
esconder, diante de seu Outro, a nudez de seu próprio rosto. Nudez que, na linha do pensamento do filósofo, revelaria sua fragilidade e seu risco de morte.

A plurivalência de Lavoura Arcaica, particularmente por sua localização no âmbito do literário, mas também por seu diálogo com o pensamento filosófico, não nos permite, no entanto, simplificações, e é por meio do rosto, da feminidade, e da habitação - presentes, à sua forma, no capítulo 18, aquele da relação incestuosa dos irmãos - mas também do Discurso plúrimo que aí se apresenta, entre o sagrado e o profano, que vemos a obra de Nassar abrir-se - através de múltiplos processos tradutórios - em camadas de profundidade. Afinal, se, enquanto ocorrência vocabular, "acolhimento" só aparece uma vez, e de forma negativa, os Capítulos 17 e 18 versam duplamente sobre o acolhimento do Outro. Anoto as três ocorrências em que a presença de Ana se anuncia, como que em mantra litúrgico:

(...) olhando ainda com desconfiança pra minha janela, o corpo de campônia, os pés descalços, a roupa em desleixo cheia de graça, branco branco o rosto branco e eu me lembrei das pombas, as pombas da minha infância (...)

ela estava lá, branco branco o rosto branco e eu podia sentir toda dubiedade, o tumulto e suas dores, e pude pensar cheio de fé eu não me engano neste incêndio, nesta paixão, neste delírio (...)

ela estava agora diante de mim, de pé ali na entrada, branco branco o rosto branco filtrando as cores antigas de emoções tão diferentes, compondo com a moldura da porta o quadro que ainda não sei onde penduro, se no corre-corre da vida, se na corrente da morte (...) (NASSAR, 1989, p. 95-97).

Ao buscar traçar o diálogo entre o literato e o filósofo, e tendo encontrado a máscara em Nassar, ali onde procurava o acolhimento e o rosto, fui em busca de "máscara" ("masque") em "Totalidade e Infinito", e pude perceber a forma com que dialoga, contraditoriamente, com o rosto, algo que não deve ter passado desapercebido por Nassar.

\section{Conclusão}

Sem muito espaço para me estender em mais explicações, quis apontar para o trabalho criativo de tradução, de repetição e de deslocamento inerente ao quefazer poético. Para tanto, debrucei-me sobre escolhas vocabulares e sequências léxicosintáticas, de forma a esmiuçar fenômenos de tradução internos aos textos, ou entre textos, ou na arquitetura dos textos, de preferência a fenômenos que apontariam para influências de questões sociais, socioeconômicas ou político-sociais sobre os textos, ou de certos textos sobre outros textos, de forma relativamente externa ou mecanicista. Aponto, de resto, para mais uma dificuldade na tradução literária, já que cabe ao tradutor - além das dificuldades linguísticas e culturais - se dar conta dessas arquiteturas textuais e ficar alerta para os itens lexicais com que se constroem.

Entendo, ainda, que o caso em particular do diálogo entre Nassar e Levinas, em que acompanhamos a forma com que o texto literário traduz elementos do texto filosófico, é bastante propício para se pensar nas características próprias aos fenômenos de tradução, na medida em que pudemos acompanhar duas ocorrências bastante distintas (uma própria ao discurso literário, e a outra, ao filosófico) de subjetivação da linguagem, com a caracterização léxico-sintática dela decorrente, assim como a criação de mundos como palcos que se abrem para a vivência da linguagem, para sua 
experimentação. O que temos, assim, de preferência, são processos criativos em que a linguagem se debruça sobre a linguagem e a retrabalha. E com isso traduz, dentro de uma vertente ainda pouquíssimo explorada nos Estudos de Tradução, que nos conduz à convicção de que todo texto já comporta, desde a origem, uma tradução.

É nessa medida, de resto, que a escritura será sempre crítica, por necessidade vital, em busca de sua própria historicidade, em processos em que o próprio funcionamento da linguagem diz mais que eventuais tematizações.

\section{REFERÊNCIAS}

DEGUY, Michel. Un serial killer: Henri Meschonnic. Sommaire, 165, Presses Universitaires de France, 2001, pp. 110-112.

DELEUZE, G. Diferença e repetição. Rio de Janeiro: Graal, 1988.

FRANCHI, Carlos. Linguagem - Atividade Constitutiva. Cadernos de Estudos Linguísticos. Campinas, n. 22, pp. 9-39, 1992.

JAKOBSON, Roman. Aspectos linguísticos da tradução. In: Linguística e comunicação. São Paulo: Cultrix, 1959.

LEVINAS, Emmanuel. Totalité et Infini. Essai sur 1'extériorité. Paris: Kluwer Academic, 2017 [1961].

LOTMAN, Juri. On the semiosphere. Sign Systems Studies. 33.1, 2005.

MARTINS, M. S. C. Ecos da Antígona na Lavoura de Nassar. Translatio. Porto Alegre: Universidade Federal do Rio Grande do Sul, 2017. http://seer.ufrgs.br/index.php/translatio/article/view/70434

MARTINS, Maria Sílvia Cintra. Emmanuel Levinas e Raduan Nassar: entre o rosto e a máscara (no prelo).

MESCHONNIC, Henri. Critique du rythme: anthropologie historique du language. Paris: Verdier, 1982.

MESCHONNIC, Henri. Poética do Traduzir. São Paulo: Perspectiva, 2010.

NASSAR, Raduan. Lavoura Arcaica. São Paulo: Companhia das Letras, 1975.

NASSAR, Raduan. Lavoura Arcaica. São Paulo: Companhia das Letras, 1989.

NASSAR, Raduan. Ancient Tillage. London: Penguin Books, 2016.

ROSENFIELD, Kathrin H. Antígona, Intriga e enigma. Sófocles lido por Hölderlin. São Paulo: Perspectiva, 2016.

VIVEIROS DE CASTRO, Eduardo. Metafísicas Canibais: Elementos para uma antropologia pós-estrutural. São Paulo: Cosac Naify, 2015. 
Data de envio: 29-03-2018

Data de aprovação: 28-06-2018

Data de publicação: 15-08-2018 